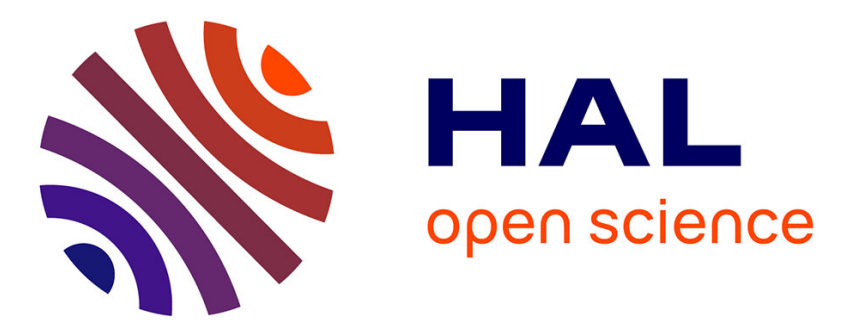

\title{
Screening for psychopathology in child welfare: the Strengths and Difficulties Questionnaire (SDQ) compared with the Achenbach System of Empirically Based Assessment (ASEBA)
}

Astrid Janssens, Dirk Deboutte

\section{To cite this version:}

Astrid Janssens, Dirk Deboutte. Screening for psychopathology in child welfare: the Strengths and Difficulties Questionnaire (SDQ) compared with the Achenbach System of Empirically Based Assessment (ASEBA). European Child and Adolescent Psychiatry, 2009, 18 (11), pp.691-700. 10.1007/s00787009-0030-y . hal-00535156

\author{
HAL Id: hal-00535156 \\ https://hal.science/hal-00535156
}

Submitted on 11 Nov 2010

HAL is a multi-disciplinary open access archive for the deposit and dissemination of scientific research documents, whether they are published or not. The documents may come from teaching and research institutions in France or abroad, or from public or private research centers.
L'archive ouverte pluridisciplinaire HAL, est destinée au dépôt et à la diffusion de documents scientifiques de niveau recherche, publiés ou non, émanant des établissements d'enseignement et de recherche français ou étrangers, des laboratoires publics ou privés. 


\title{
Screening for psychopathology in child welfare: the Strengths and Difficulties Questionnaire (SDQ) compared with the Achenbach System of Empirically Based Assessment (ASEBA)
}

\author{
Astrid Janssens · Dirk Deboutte
}

Received: 18 January 2008/Accepted: 1 May 2009/Published online: 22 May 2009

(C) Springer-Verlag 2009

\begin{abstract}
Whilst children in child welfare suffer more psychopathology than their community peers, only a small percentage of them actually receive mental health care. Previous literature suggested that all children entering child welfare should be screened. This study evaluated whether the Strengths and Difficulties Questionnaire (SDQ) could be used for this purpose. The extended version of the SDQ and the Achenbach System of Empirically Based Assessment (ASEBA) questionnaire were administered to parents and caregivers of 292 children in child welfare. Children older than 11 years also completed the SDQ self-report and the Youth Self Report (YSR). Furthermore, the child's history of service use was recorded and informants were asked if the actual care was sufficient. Inter-informant correlations for the scores from the SDQ and ASEBA were high and comparable or favoured the use of the SDQ (for parents and caregivers). Internal consistency was satisfactory to good. For all informants, high correlations were found between SDQ and ASEBA. Despite high scores on the SDQ, only $29 \%$ of the children had received mental health care. Service use was only correlated with the parent SDQ and the CBCL and TRF. Additional help, as requested by $21 \%$ of the parents and $37 \%$ of the caregivers, correlated moderately with the SDQ and ASEBA scores. Compared to the total difficulties score, the impact supplement is a better predictor of service use and the informant's request for
\end{abstract}

\footnotetext{
A. Janssens $(\bowtie) \cdot$ D. Deboutte

University Centre Child and Adolescent Psychiatry Antwerp (UCKJA), Collaborative Antwerp Psychiatric Research Institute (CAPRI), University of Antwerp, Universiteitsplein 1, Building R 3:23, 2610 Antwerp, Belgium

e-mail: astrid.janssens@ua.ac.be

D. Deboutte

e-mail: dirk.deboutte@ua.ac.be
}

additional help. This study illustrates that the Dutch version of the SDQ, similar to the English and German versions, has equal validity as the Dutch ASEBA for screening children. Caution is warranted when the SDQ is the only source of information for referrals to specialized care.

Keywords Child welfare · Screening · Psychopathology · Strengths and Difficulties Questionnaire (SDQ) . Achenbach System of Empirically Based Assessment (ASEBA)

\section{Introduction}

Prevalence studies have indicated that children in child welfare suffer two to seven times more psychopathology compared to their peers $[10,13,15]$. Children in foster care show an increased prevalence of psychopathology that range from 15 to $57 \%[6,14,24,30,32,38]$. The prevalence rates for children living in residential care are even higher, ranging from 34 to $86 \%$ [5, 23, 27].

Despite these high levels of psychopathology, only a small percentage of these children actually receive additional help [10]. A study of social workers' views about the mental health needs of a sample of foster children illustrated that social workers perceived a need for professional help in $80 \%$ of the children, whilst only $27 \%$ received any input [37]. In addition to service factors such as placement instability, poor mental health resources and insufficient funding, social workers appear to lack confidence about when they should refer children to (specialized) mental health services.

Consequently, prominent organizations [4] and many authors [10, 15, 25] advocate for timely referrals through an early and generalized screening. 
Different instruments are available to screen for behavioural and emotional problems. The Achenbach System of Empirically Based Assessment (ASEBA) has been used most frequently to assess child psychopathology. This tool consists of questionnaires to be administered by the parent, teacher and children, aged 11 years and older. The validity and reliability of the ASEBA has been demonstrated across different cultures [12]. The Strengths and Difficulties Questionnaire (SDQ) is a more recently developed brief measure to screen for behavioural and emotional problems with children and adolescents [17]. The 25-item questionnaire can be completed by different informants, i.e. parents, teachers and adolescents, and is available in over 40 different languages (see http://www. sdqinfo.com). The instrument has been studied in both community and clinical samples in different countries [19, 28, 31, 35, 36, 42].

The SDQ and ASEBA, however, differ on several dimensions that may tip the balance in favour of one of them. The most obvious difference is the length of the questionnaires: the SDQ contains 25 items on psychopathology, whilst the ASEBA contains a minimum of 118 items. The SDQ uses positively phrased items, whereas the ASEBA is composed entirely of negative items. Both of the above-mentioned differences could also influence the acceptability of the questionnaire [21]. The difference in underlying diagnostic models could influence the validity of the instruments. Finally, there is an extended version of the SDQ, with an impact supplement to explore the child's or adolescent's impairment in four domains.

The purpose of this study was to evaluate whether the Dutch version of the SDQ is a suitable screening tool for children in child welfare. Secondly, we explored whether the SDQ's total difficulties score and or impact score could be used as indicators to identify children in need for (professional) help.

\section{Methods}

\section{Sample}

Data were collected in 16 child welfare institutions in the region of Antwerp (Belgium) with a total capacity of 556 children (for a detailed overview of the organization of child welfare and its services, see Hellinckx and Grietens [24]). These institutions are representative of the Flemish institutions with regard to capacity of different types of placements, gender and age distribution. At the moment of the survey, 455 Dutch-speaking children and adolescents between 3 and 18 were receiving care by one of the selected institutions. A total of 79 children were ineligible for the study because they had been in care for less than
4 weeks, which was considered the minimum duration to allow caregivers to know the child well enough.

All children who were receiving care for 4 weeks or more, their (foster) parents and all responsible agency key caregivers (further on referred to as caregivers) were informed about the study and invited to participate. The extended version of the SDQ, the ASEBA form and a short questionnaire to collect data regarding socio-economic status and (mental health) service use were administered. The researchers distributed the questionnaires amongst all responsible caregivers and the caregivers asked the parents and the adolescents to complete their forms. Written consent was obtained from all respondents.

As much as $22 \%$ of the eligible children $(N=376)$ did not participate for one of the following reasons: parents could not be located, children had left the institution before questionnaires could be completed or refusal to participate (without the reason being specified).

At least one completed questionnaire was received for 292 children $(M=12.13 ; \mathrm{SD}=4.28)$, of whom 131 (45\%) were boys. Gender was equally distributed over the three age groups, $\left.\chi^{2}(2, N=278)=1.44, \mathrm{~ns}\right)$. The majority of the children $(57 \%)$ were older than 11 years, $32 \%$ were between 3 and 5 years, and $11 \%$ were between 3 and 5 years old. Most of these children were from socially deprived families; half of them (53\%) were from singleparent families. Approximately, one-third of the mothers (29\%) supported their family, on average consisting of 3.51 children, with less than $800 €$, whilst $876.5 €$ is considered the minimum required income for a family with at least one minor. More than half of the parents $(56 \%)$ had completed only elementary school, whilst $15 \%$ had never finished elementary school.

\section{Preceding questionnaire}

A self-developed questionnaire to record socio-economic characteristics, mental health service use and child welfare history preceded the questionnaires on psychopathology. The mental health service history of the child (referred to as 'service use') was investigated through a multiple choice question including different mental health services and a blank option to add non-stated services. The question was presented to parents and caregivers only. The information was analysed as a dichotomized variable: no contact versus previous and or current contact with mental health services. Another variable (referred to as 'need-question') captured the respondents' felt need for additional support. The informant was asked whether the care that the child was receiving at the time of the enquiry was sufficient or whether additional help (not further specified as mental health care or any other) would be appropriate. 
Strengths and Difficulties Questionnaire (SDQ)

The extended SDQ comprises a 25-item informant-rated SDQ plus an informant-specific impact supplement. The questionnaire contains positive and negative items that need to be rated as 'not true' $(0)$, 'somewhat true' (1) or 'certainly true' (2). Goodman [17, 20] described five items to construct five subscales: emotional symptoms, conduct problems, hyperactivity-inattention, peer problems and prosocial behaviour. The scores for these subscales are compiled by adding the scores for the five corresponding items, after recoding the scores of positively phrased items ( 0 becomes 2 and 2 becomes 0 ). The sum of four of the five subscale scores (the prosocial scale is excluded) yields a total difficulties score. The impact supplement includes questions about social impairment in four domains: home life (not for teacher or caregiver), friendships, classroom learning and leisure activities (not for teacher or caregiver).

The Dutch versions of the SDQs for parents, teachers and youth were first translated in 2000 [41] and can be downloaded from the Web site (http://www.sdqinfo.com). Alternate versions were used for children aged 3-4 years. The psychometric properties of the Dutch version were described in subsequent studies in a Dutch [43] and Flemish community sample [42].

Because there is no Flemish normative sample and the Dutch was found to be biased [16], cases were allocated to a reference, a borderline or a clinical range of the scoring distributions according to the British normative sample [33]. For parents, clinical functioning was defined as scoring 16 or higher. The cutoff point for the agency carer's and adolescents' scores were respectively, 15 and 19.

Achenbach System of Empirically Based Assessment (CBCL, TRF, YSR, CBCL/1.5-5, C-TRF)

Dutch versions [44-46] of the different ASEBA questionnaires, the CBCL, TRF and YSR were administered to all parents, caregivers and children older than 11 years. For children younger than 6 years, the Child Behavior Checklist for ages 1.5-5 (CBCL/1.5-5) and CaregiverTeacher Report form for ages 1.5-5 (C-TRF) were used. Items are scored on a three-point scale, allowing to calculate a total, externalizing and internalizing score, as well as a score for eight individual scales. The psychometric properties of the CBCL, TRF and YSR are well known and conveniently summarized [1-3].

\section{Statistical analysis}

Data analysis was performed with SPSS version 14 (SPSS Inc., 1999). The employed evaluation methods included inter-rater correlations and scale reliability analyses yielding measures of internal consistency (Cronbach's alpha). The concurrent validity of the SDQ was tested by computing the Pearson product-moment correlation between the SDQ total and subscale scores and the corresponding ASEBA scores. A Fisher's Z-transformation was used to compare the corresponding inter-rater correlations of the total and subscale SDQ and ASEBA scores. Cohen's Kappa for inter-rater reliability was used to assess the agreement between two different raters concerning the requested additional help.

A $t$ test for independent samples was used to compare mean SDQ scores amongst boys and girls. One-sample $t$ tests were performed to assess the deviance from the British SDQ norm means.

Requested additional help (no/yes) and service use (no/ yes) were modelled using binary logistic regression analyses. For all three informants, an 'enter' approach was applied, modelling SDQ total difficulties and impact scores as independent variables.

Even though the prosocial scale of the SDQ and the Competence scale of the ASEBA share a focus on positive attributes, they were not compared because of the marked difference in their content. The analysis of the Social (ASEBA) versus Peer (SDQ) scale and Hyperactivity (SDQ) versus Attention problems (ASEBA) scale were not performed on data from children younger than 6 years. The content of the Social and Hyperactivity scale of the CBCL/ 1.5-5 and C-TRF differed too much from the content of the CBCL and TRF to allow merging data.

\section{Non-response analysis}

In this study, there were two types of non-respondents: (1) cases missing all data ( 84 children) and (2) cases missing only part of the data (for 159 children there was at least one valid questionnaire with less than 3 blank answers). There were no or invalid data for 69 parental SDQs, 69 CBCLs, 29 caregiver SDQs, 104 TRFs, 19 self-report SDQs and 25 YSRs.

The influence of the first kind of non-response cannot be estimated. Comparison of the means of the remaining informants of children of responding and non-responding informants gives an idea of the influence of the second kind of non-response. According to the caregiver SDQ-scores, children from non-responding parents showed lower total difficulties and lower peer problems scores than children from responding parents, respectively: 12.83 versus 14.60 , $t(261 d f)=-2,18 \quad(P<0.05)$ and 2.25 versus 2.89, $t$ (unequal variances, 261) $=-2.89(P<0.005)$. For the self-report SDQ scales, however, there were no differences between the scores for children from responding and those from non-responding parents. Comparison of the parent SDQ scores and the self-report SDQ scores for children who had complete caregivers' SDQ data and those who had incomplete caregivers' information revealed no differences. 


\section{Results}

\section{Mean SDQ scores}

Table 1 presents the mean SDQ scores for the different informants. Girls scored higher than boys on the emotional scale according to parent ratings $(t(222 d f)=2.03, P<0.05)$ and self-report ratings $(t(145 d f)=-4.15, P<0.0001)$, as well as on the prosocial behaviour scale according to caregiver ratings $(t(262 d f)=-2.91, P<0,005)$. Girls scored lower than boys on the hyperactivity/inattention scale according to parent and caregiver ratings (respectively $t(222 d f)=3.23, P<0.001$ and $t(262 d f)=3.24, P<0.001)$.

Table 1 also summarizes the differences between the study populations' mean scores and the corresponding British norm means in terms of standard deviations (SD). The results of the one-sample $t$ tests illustrate that these differences were highly significant for all mean scores for all informants.

\section{Internal consistency}

As shown in Table 1, Cronbach's alpha coefficients for the parent and teacher SDQ scales demonstrate good internal consistency: mean $\alpha$, respectively, 0.72 and 0.75 . The internal consistency was lowest for the self-report scales, with a mean $\alpha$ of 0.62 .

\section{Inter-rater correlations}

The inter-rater correlations for both instruments show comparable results (see Table 2). The results suggest better agreement amongst informants when using the SDQ. The difference between the Fisher's Z-transformed correlations was statistically significant only for the parent-caregiver subscales correlation 'hyperactivity/attention' and 'peer/ social'.

\section{Concurrent validity}

Table 3 illustrates that most of the correlations between the SDQ and ASEBA scores were very strong and equally high as the internal consistency of the scales. There were strong correlations between the subscale scores and the total score of the parent-rated SDQ and the CBCL, except for the moderate correlations between peer problems scale (SDQ) and the social scale (ASEBA). The correlations between the subscales of the self-report SDQ and the YSR, as well as those between the subscales of the caregiver SDQ and the TRF, showed a similar pattern.

\section{Service use}

Service use data were available for 235 children of whom 68 children had or were having contact with at least one mental health service. Of those children of whom the parent, caregiver or the adolescent himself or herself scored within the clinical range on the SDQ, respectively, 36, 33 and $41 \%$ received help from a mental health service. An overview of the raw data is presented in Table 4.

Service use correlates significantly with the following parental scores: SDQ total difficulties score $(r=0.16$; $P<0.05)$, SDQ emotional symptoms $\quad(r=0.15$; $P<0.05)$, SDQ peer problems $(r=0.15 ; P<0.05)$, CBCL/CBCL1.5-5 total problems $(r=0.20 ; P<0.005)$, internalizing $(r=0.22 ; P<0.005)$ and externalizing scores $(r=0.15 ; P<0.05)$. Significant correlations were found between service use and the TRF/C-TRF total

Table 1 Mean SDQ scores and Cronbach's alpha coefficients according to informant

\begin{tabular}{|c|c|c|c|c|c|c|}
\hline & \multicolumn{3}{|c|}{ Mean scores (SD) } & \multicolumn{3}{|c|}{ Cronbach's alpha } \\
\hline & $\begin{array}{l}\text { Parent } \\
N=223\end{array}$ & $\begin{array}{l}\text { Caregiver } \\
N=263\end{array}$ & $\begin{array}{l}\text { Self } \\
N=146\end{array}$ & $\begin{array}{l}\text { Parent } \\
N=223\end{array}$ & $\begin{array}{l}\text { Caregiver } \\
N=263\end{array}$ & $\begin{array}{l}\text { Self } \\
N=146\end{array}$ \\
\hline Total Difficulties & $16.39^{\mathrm{b}}(7.63)$ & $14.60^{\mathrm{b}}(7.17)$ & $14.38^{\mathrm{a}}(5.84)$ & 0.84 & 0.84 & 0.75 \\
\hline Emotional symptoms & $4.14^{\mathrm{b}}(2.60)$ & $4.15^{\mathrm{b}}(2.60)$ & $3.86^{\mathrm{a}}(2.55)$ & 0.70 & 0.72 & 0.71 \\
\hline Conduct problems & $3.74^{\mathrm{b}}(2.69)$ & $3.08^{\mathrm{b}}(2.53)$ & $2.95(2.05)$ & 0.76 & 0.77 & 0.66 \\
\hline Hyperactivity & $5.54^{\mathrm{a}}(2.84)$ & $4.54^{\mathrm{a}}(2.91)$ & $4.84(2.25)$ & 0.77 & 0.82 & 0.63 \\
\hline Peer problems & $2.97^{\mathrm{a}}(2.23)$ & $2.89^{\mathrm{a}}(2.20)$ & $2.74^{\mathrm{a}}(1.89)$ & 0.59 & 0.66 & 0.39 \\
\hline Prosocial behaviour & $7.06^{\mathrm{e}}(2.43)$ & $6.50(2.37)$ & $7.60(1.91)$ & 0.76 & 0.79 & 0.68 \\
\hline Impact supplement & $2.16^{\mathrm{c}}(2.53)$ & $2.43^{\mathrm{d}}(2.30)$ & $1.19^{\mathrm{b}}(1.97)$ & & & \\
\hline \multicolumn{7}{|c|}{ a $0.5-1.0 \mathrm{SD}$ above uk-mean } \\
\hline \multicolumn{7}{|c|}{ b $1.0-1.5$ SD above uk-mean } \\
\hline \multicolumn{7}{|c|}{ c 1.5-2.0 SD above uk-mean } \\
\hline \multicolumn{7}{|c|}{${ }^{\mathrm{d}}>2 \mathrm{SD}$ above uk-mean } \\
\hline e $0.5-1.0 \mathrm{SD}$ under $\mathrm{ul}$ & (http://www.sc & om) & & & & \\
\hline
\end{tabular}




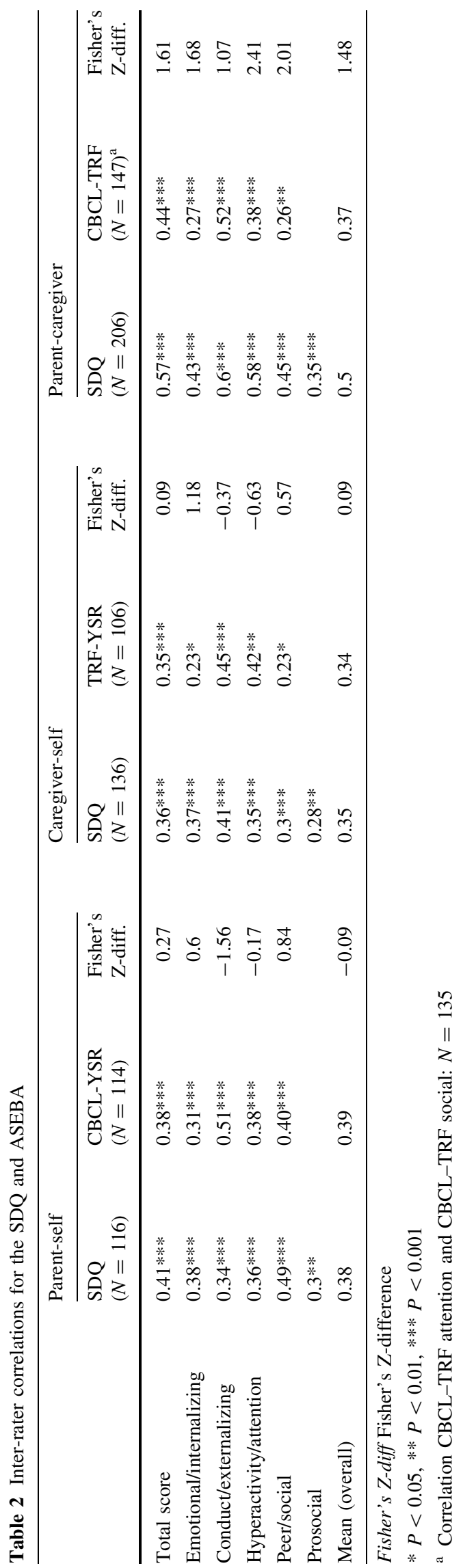

Table 3 Correlations of equivalent SDQ and ASEBA scales for three informants

\begin{tabular}{llll}
\hline & $\begin{array}{l}\text { Parent } \\
(N=218)^{\mathrm{a}}\end{array}$ & $\begin{array}{l}\text { Caregiver } \\
(N=184)^{\mathrm{b}}\end{array}$ & $\begin{array}{l}\text { Self } \\
(N=139)\end{array}$ \\
\hline Total score & 0.81 & 0.71 & 0.75 \\
Emotional/internalizing & 0.70 & 0.69 & 0.71 \\
$\begin{array}{l}\text { Conduct/externalizing } \\
\begin{array}{l}\text { Hyperactivity/attention } \\
\text { problems }\end{array}\end{array}$ & 0.81 & 0.69 & 0.56 \\
$\begin{array}{l}\text { Peer/social } \\
\text { Mean correlation for the }\end{array}$ & 0.63 & 0.62 & 0.63 \\
$\quad$ subscales & 0.67 & 0.59 & 0.51 \\
\hline
\end{tabular}

${ }^{\text {a }}$ Correlation SDQ-CBCL peer/social and hyperactivity/attention problems: $N=196$

${ }^{\mathrm{b}}$ Correlation SDQ-TRF peer/social and hyperactivity/attention problems: $N=171$

All correlations are significant at $P<0.001$

Table 4 Requested additional help and service use by SDQ caseness

\begin{tabular}{|c|c|c|c|c|c|c|c|c|}
\hline \multirow[t]{3}{*}{ Rater } & \multicolumn{6}{|c|}{ Requested additional help } & \multicolumn{2}{|c|}{ Service use } \\
\hline & \multicolumn{2}{|c|}{ Parent } & \multicolumn{2}{|c|}{ Caregiver } & \multicolumn{2}{|c|}{ Youngster } & \multirow[b]{2}{*}{ No } & \multirow[b]{2}{*}{ Yes } \\
\hline & No & Yes & No & Yes & No & Yes & & \\
\hline \multicolumn{9}{|l|}{ Parent } \\
\hline SDQ low & 99 & 8 & 117 & 50 & 77 & 9 & 77 & 28 \\
\hline SDQ high & 75 & 32 & 12 & 25 & 17 & 2 & 68 & 39 \\
\hline \multicolumn{9}{|l|}{ Caregiver } \\
\hline SDQ low & & & 111 & 35 & 74 & 9 & 91 & 33 \\
\hline SDQ high & & & 51 & 59 & 44 & 4 & 60 & 29 \\
\hline \multicolumn{9}{|l|}{ Youngster } \\
\hline SDQ low & & & & & 102 & 11 & 62 & 30 \\
\hline SDQ high & & & & & 24 & 4 & 13 & 9 \\
\hline
\end{tabular}

Numbers in italic: replace SDQ low/high in the second column by requested additional help no/yes

problems $(r=0.17, P<0.05)$ and internalizing scores $(r=0.17 ; P<0.05)$. No correlation with service use was found for the caregiver SDQ, self-report SDQ and the YSR.

Requested additional help

The received care at the time of the inquiry was considered insufficient for $18 \%$ of the children according to the parents, and for $37 \%$ of the children according to the caregivers. Parents and caregivers requested additional help for, respectively, 21 and $42 \%$ of the children who were previously in contact with mental health services. Only 15 of 141 (10\%) adolescents demanded more help, but amongst those who had previous contacts with mental health services, $18 \%$ asked for additional support. The raw data are presented in Table 4. 
Table 5 Correlation between the need-question and SDQ or ASEBA scores, according to informant

\begin{tabular}{|c|c|c|c|c|c|c|}
\hline & \multicolumn{2}{|l|}{ Parent } & \multicolumn{2}{|l|}{ Caregiver } & \multicolumn{2}{|l|}{ Self } \\
\hline & SDQ $(N=214)$ & CBCL $(213)^{a}$ & SDQ $(N=258)$ & $\operatorname{TRF}(N=182)^{\mathrm{b}}$ & SDQ $(N=140)$ & YSR $(N=134)$ \\
\hline Total score & $0.34 * * *$ & $0.40 * * *$ & $0.38 * * *$ & $0.33 * * *$ & 0.11 & $0.26 * *$ \\
\hline Emotional/internalizing & $0.28 * * *$ & $0.37 * * *$ & $0.29 * * *$ & $0.28 * * *$ & 0.16 & $0.25 * *$ \\
\hline Conduct/externalizing & $0.29 * * *$ & $0.40 * * *$ & $0.30 * * *$ & $0.28 * * *$ & 0.08 & $0.18 *$ \\
\hline Hyperactivity/attention & $0.17 *$ & $0.34 * * *$ & $0.25 * * *$ & $0.30 * * *$ & 0.05 & 0.12 \\
\hline Peer/social & $0.27 * * *$ & $0.29 * * *$ & $0.20 * * *$ & 0.15 & -0.01 & 0.16 \\
\hline Prosocial & $-0.20 * *$ & & -0.12 & & 0.07 & \\
\hline
\end{tabular}

$* P<0.05, * * P<0.01$, *** $P<0.001$

${ }^{\text {a }}$ For attention and social problems: $N=190$

${ }^{\mathrm{b}}$ For attention and social problems: $N=169$

Parents and caregivers agree on whether or not they demanded additional help, in 142 out of 204 cases (70\%; $\kappa=0.28, P<0.001)$. There was, however, no agreement between the adolescent's judgement concerning the need for additional help and the judgements of their parents and caregivers. Table 5 gives an overview of the correlations between the demand for additional support of the different informants and their respective (sub-)scale scores on both instruments. SDQ and ASEBA total difficulties and subscale scores of parents and caregivers correlate significantly with the demand for additional support, whilst there was no correlation with the self-reported questionnaires (SDQ and YSR).

The impact supplement

The proportion of subjects meeting the definition for impact caseness (having a score of two or more for the impact supplement) was, respectively, 49, 55 and $28 \%$, according to the parent's, caregiver's and adolescent's report. Overall, $63 \%$ of the subjects met the impact caseness criteria according to at least one informant.

The predictive power of the total difficulties score versus the impact score

For all three informants, a binary logistic regression was performed with impact score and total difficulties score as the independent variables and service use (no versus previous mental health contact) and need-question (no versus additional help requested by the informant) as dependent variables.

Caregiver-rated impact scores contributed significantly to the prediction of service use: odds ratio $(\mathrm{OR})=1.30$ $(P<0.005)$; however, the contribution of caregiver-rated total difficulties scores was not significant $(\mathrm{OR}=0.97)$. There was no significant contribution to the prediction of service use from the parent-rated and the adolescent-rated impact score and total difficulties score.

When repeating the analysis to predict the need for additional help, the impact score made a significant contribution to the prediction of the caregiver's request for additional support (OR: 1.37, $P<0.0001)$ and the parent's request for additional support (OR: 1.50, $P<0.0001$ ). Parent's (OR: 1.07, $P=0.06$ ) and caregiver's (OR: 1.03 , $P=0.27$ ) total difficulties scores made no significant contribution. The adolescent's request for additional help could not be predicted by either of these scores.

\section{Discussion}

Many studies have established high prevalence rates amongst children in child welfare and contrasting low rates of received specialized care. The aim of this study was to examine the suitability of the SDQ as a screening and or referral tool for child welfare populations.

The SDQ versus the ASEBA: psychometric characteristics

The inter-rater agreement between the SDQ total scores according to self-report, parent-rating and caregiver-rating, was moderate to good $(r=0.36-0.57)$. The inter-rater correlations between parent-rated and self-reported SDQ, as well as between caregiver-rated and self-reported SDQ, were comparable to those of the corresponding ASEBA inter-informant correlations. The parent-caregiver agreement was better for the SDQ and significantly better for the hyperactivity and peer problems subscales. All other correlations were similar to those reported by a previous study in a clinical sample [20].

The internal consistency (measured by Cronbach's alpha) of the parent-rated and caregiver-rated SDQ was 
good (0.59-0.84) and generally satisfactory $(0.39-0.75)$ for the self-report SDQ. Our results for the parental version are comparable to those from other studies, with exception of the results for the subscale 'conduct problems'. All other studies reported a drop-out in the internal consistency for 'conduct problems' and 'peer problems', whereas our study confirmed only the rather low internal consistency for 'peer problems' $[19,35,40,42,43]$. Our internal consistency of the caregiver SDQ was comparable to the results of Goodman [19] and van Widenfelt et al. [43]. The selfreport SDQ findings were similar to those of Muris et al. [35], but showed a more pronounced dropout for the peer problems subscale than in the studies of Goodman [19] and van Widenfelt et al. [43].

The concurrent validity of the SDQ, assessed by the correlation with the corresponding ASEBA-questionnaires, was good. The parent SDQ-CBCL correlation was lower than that reported by Goodman and Scott [21], comparable to that reported by van Widenfelt et al. [43] and Klasen et al. [28], and higher than the results found by Koskelainen et al. [29], Muris et al. [35] and Van Leeuwen et al. [42]. The latter reported caregiver SDQ-TRF correlations similar to our results. Muris et al. [35] found equal correlations for the self-report version of the SDQ and YSR. All these studies reported a rather weak correlation between social problems (ASEBA) and peer problems (SDQ) for all informants, which was also confirmed in this study.

The SDQ total difficulties score as a screening instrument

\section{Mean SDQ scores}

The mean parental and caregiver SDQ total difficulties and subscale scores were 1.5 standard deviation higher than the UK norm data. Neither the self-report subscales scores nor the mean total difficulties score were more than one standard deviation above the UK norm scores. The results for the self-report SDQ suggested that children whose parents or caregiver clearly indicated emotional and behavioural problems did not perceive themselves as having mental health problems.

In contrast to the scores on the parental and caregiver SDQ and the psychopathology rates in such populations, the percentage of adolescents who perceived they had a mental health problem according to the self-report SDQ only was $20 \%$. Goodman et al. [20] already described this phenomenon; these findings underline that it is imperative to use a multi-informant approach, both in epidemiological studies and clinical practice. Referring these young people to (professional mental health) assistance is challenging because of the high likelihood if it not being embraced by the child.

\section{Mental health service use}

In this study, 29\% of the children had (previously) contacts with mental health care. These findings are in line with the estimates of the Health Advisory Service [22] for children treated by Child Welfare services. The SDQ and ASEBA scores show a low, though sometimes significant, correlation with service use. Including service use as a validation criterion yields a sensitivity of 58 and $47 \%$ for the parent and caregiver SDQ, respectively, and a specificity of 53 and $49 \%$, respectively.

The SDQ total difficulties score as a referral tool

\section{Requested additional care}

At the time of the inquiry, $18 \%$ of the parents and $37 \%$ of the caregivers requested additional care for the child in question. Eight out of ten children for whom parents requested additional help (40/214) scored within the clinical range and almost two-third (94/256) of the children for whom caregivers requested additional help scored within the clinical range.

Surprisingly, $46 \%$ of the caregivers and $70 \%$ of the parents did not identify any additional needs (besides those covered by child welfare) for children subsequently identified through the SDQ screen. One could assume that the provided assistance of child welfare was sufficient for these children, even for those children with psychopathology. If so, these results might illustrate that children scoring above a caseness cutoff are not necessarily in need of additional professional help. On the other hand, these high rates of intuitively non-identified designated cases based on the SDQ screen might reflect actual needs amongst children. This would confirm the hypothesis of Philips [37] that professionals lack the confidence and perhaps the necessary skills to identify these problems, and training is required. What is more, $23 \%$ of the children clinically assessed by the caregiver as not having a disorder were categorized by the caregiver to be in need of additional support. Not reaching 'clinical levels', however, does not imply that the child has no difficulties, for which additional help might be requested.

This should all be kept in mind when using the SDQ as a referral tool. The request of parents, caregivers and children for additional help is important information that needs to be taken into account when making referrals to specialized care, especially since most of these services are already overcrowded.

The SDQ impact score as a referral tool

Administering the extended version of the SDQ could compensate for the average predictive value of the SDQ 
total difficulties score. The impact supplement explicitly asks the informant if he or she thinks the young person has a problem, and, if so, enquires further about the level of chronicity, distress, social impairment and the impact of the burden on others. A study of Goodman [18] illustrated that impact scores can better discriminate between clinical and community subjects than can the total difficulties scores. The best prediction was achieved when both the impact and the symptoms score were used. The regression analysis performed in this study confirmed Goodman's statement that the impact supplement is a better predictor for service use. Predicting the informant's request for additional help based on the impact score yielded even more distinct results.

\section{Study limitations}

This study has important strengths, but also several limitations that require discussion. The response rate of $78 \%$ is rather good, given the population under study. Children and adolescents in child welfare have always been a difficult group to study: frequent changes of placements, changes in social worker, poor school attendance and young people's mistrust towards such initiatives present significant challenges to researchers. A low response rate amongst this population is not rare. Many studies reported recruitment difficulties in this population [9, 15, 39], even when adolescents were paid to participate in the study [34]. In order to respect the privacy of the children, we did not explore information on gender, age, condition or situation of the non-responders. This made it impossible to estimate how well the study sample represents the larger group.

Besides missing data, non-response analyses revealed that our sample of parent SDQs was biased for parental non-response. Caregivers' SDQ total difficulties scores and peer problems scores were lower for children from nonresponding parents compared to responding parents. As a result of the documented high correlation between caregiver-rated and parent-rated SDQ scores, it can be assumed that parents' response rate was lower for children with low parental SDQ scores. Presumably, parents who did not experience difficulties with their child did not find it relevant to complete the questionnaires (the response rate for both questionnaires was identical), whilst parents with concerns about their child may have taken it as an opportunity to raise this issue. On the other hand, we have no indication that the missing data of the caregiver-rated SDQ scores caused any bias.

We used the British cutoffs norms, which are based on a population of 5-15-year olds, whereas our study population includes children between 3 and 17-year old. Moreover, previous research identified a lower $10 \%$ cutoff point for Dutch children $[11,43]$. Possibly, there is a comparable bias for Flemish children. There are, however, currently no normative data based on a Flemish community sample available.

The lack of a clinical assessment, such as a psychiatric interview, could be another important limitation. In the absence of definite criteria for the assessment of emotional and behavioural problems, any choice of a golden standard remains questionable. Although the authors agree that additional information in the form of a psychiatric diagnostic interview would be invaluable, these data could not be obtained because of its high costs. Our approach, however, has been applied in several other studies and especially in studies on SDQ [7, 8, 21, 26, 28, 31, 42, 43].

Finally, bias could have been introduced by the way we collected data concerning 'mental health service use'. Since the use of (public) mental health care in Belgium is not registered in public records, we used self-report data and had no way to control the accuracy of this information. The combining of previous and current contact with a mental health service into one question made the information less accurate and ignored the fact that problems (and their impact) could have been altered as a result of previous contacts with mental health services. The latter may have influenced correlations of total difficulties scores and impact score.

\section{Conclusion}

The high prevalence of psychopathology amongst children in child welfare compared to that of their peers and the relatively low number of referrals to specialized care illustrate that it is crucial to screen all children entering child welfare. This study confirms the good psychometric properties of the Dutch version of the SDQ, as previously reported by van Widenfelt et al. [43] and Van Leeuwen et al. [42], and suggests that the SDQ has comparable or even better psychometric properties than the ASEBA. In addition, the SDQ is considerably shorter, includes positive items, is freely available and is a less complicated score. This makes the SDQ the most preferable instrument for routine screening of children entering child welfare. However, the SDQ could possibly miss less common problems as a result of it being limited to 20 problem items only.

The SDQ could trigger caregivers and or parents to follow the child's wellbeing more closely and could indicate certain needs of the child. However, not all children with an elevated SDQ score are in need of additional care, and not all children whose caregiver or parent request additional care score within the clinical range. This leaves us with the question: how and based on which information referrals should be made. The impact score and intuitive 
judgement seem very important signals for the need for specialized help. Nevertheless, there remains a missing link between the information gathered during a mental health screening and the necessary type and intensity of the needed care.

\section{References}

1. Achenbach TM (1991a) Manual for the child behavior cekclist/418 and 1991 Profile. University of Vermont, Department of Psychiatry, Burlington

2. Achenbach TM (1991b) Manual for the teacher's report form and 1991 profile. University of Vermont, Department of Psychiatry, Burlington

3. Achenbach TM (1991c) Manual for the youth self-report form and 1991 profile. University of Vermont, Department of Psychiatry, Burlington

4. American Academy of Child and Adolescent Psychiatry and Child Welfare League of America (2002) AAACAP/CWLA Policy statement on mental health and substance use screening and assessment of children in foster care. American Academy of Child and Adolescent Psychiatry and Child Welfare League of America

5. Arcelus J, Bellerby T, Vostanis P (1999) A mental health service for young people in the care of the local authority. Clin Child Psychol Psychiatry 4:233-245

6. Armsden G, Pecora PJ, Payne V, Szatkiewicz JP (2000) Children placed in long-term foster care: an intake profile using the child behavior checklist/4-18. J Emot Behav Disord 8:49-64

7. Becker A, Hagenberg N, Roessner V, Woerner W, Rothenberger A (2004) Evaluation of the self-reported SDQ in a clinical setting: do self-reports tell us more than ratings by adult informants? Eur Child Adolesc Psychiatry 13:ii17-ii24

8. Becker A, Woerner W, Hasselhorn M, Banaschewski T, Rothenberger A (2004) Validation of the parent and teacher SDQ in a clinical sample. Eur Child Adolesc Psychiatry 13:ii11-ii16

9. Blower A, Addo A, Hodgson J, Lamington L, Towlson K (2004) Mental health of 'looked after' children: a needs assessment. Clin Child Psychol Psychiatry 9:117-129

10. Burns B, Phillips S, Wagner R, Barth R, Kolko D, Campbell Y, Landsverk J (2004) Mental health need and access to mental health services by youths involved with child welfare: a national survey. J Am Acad Child Adolesc Psychiatry 43:960-970

11. Crone M, Vogels A, Hoekstra F, Treffers P, Reijneveld S (2008) A comparison of four scoring methods based on the parent-rated strengths and difficulties questionnaire as used in the Dutch preventive child health care system. BMC Public Health 8:106

12. de Groot A, Koot HM, Verhulst FC (1994) Cross-cultural generalizability of the child behavior checklist cross-informant syndromes. Psychol Assess 6:220-230

13. Dimigen G, Del Priore C, Butler S, Evans S, Ferguson L, Swan M (1999) Psychiatric disorder among children at time of entering local authority care: questionnaire survey. Br Med J 319:675

14. Dubowitz H, Fiegelman S, Harrington D, Starr RJr, Zuravin S, Sayer R (1994) Behavior problems of children in kinship care. Dev Behav Pediatr 14:386-395

15. Garland A, Hough RL, McCabe K, Yeh M, Wood PA, Aarons GA (2001) Prevalence of psychiatric disorders in youths across five sectors of care. J Am Acad Child Adolesc Psychiatry 40:409-418

16. Goedhart A, Treffers F, Van Widenfelt BM (2003) Vragen naar psychische problemen bij kinderen en adolescenten. Maandblad Geestelijke Volksgezondheid 3:1018-1035
17. Goodman R (1997) The strengths and difficulties questionnaire: a research note. J Child Psychol Psychiatry 38:581-586

18. Goodman R (1999) The extended version of the Strengths and Difficulties Questionnaire as a guide to child psychiatric caseness and consequent burden. J Child Psychol Psychiatry 40:791-799

19. Goodman R (2001) Psychometric properties of the strengths and difficulties questionnaire. J Am Acad Child Adolesc Psychiatry 40:1337-1345

20. Goodman R, Meltzer H, Bailey V (1998) The strengths and difficulties questionnaire: a pilot study on the validity of the selfreport version. Eur Child Adolesc Psychiatry 7:125-130

21. Goodman R, Scott S (1999) Comparing the strengths and difficulties questionnaire and the child behavior checklist: is small beautiful? J Abnorm Child Psychol 27:17-24

22. Service HealthAdvisory (1995) Together we stand: the commissioning role and management of child and adolescent mental health services. HMSO, London

23. Heflinger CA, Simpkins CG, Combs-Orme T (2000) Using the CBCL to determine the clinical status of children in state custody. Child Youth Serv Rev 22:55-73

24. Hellinckx W, Grietens H (1994) Prevalence of problem behavior in foster children in Flanders. Community Altern Int J Fam Care 62:27-46

25. Hukkanen R, Sourander A, Bergroth L, Piha J (1999) Psychosocial factors and adequacy of services for children in children's homes. Eur Child Adolesc Psychiatry 8:268-275

26. Indredavik MS, Vik T, Heyerdahl S, Kusleng S, Brubakk AM (2005) Psychiatric symptoms in low birth weight adolescents, assessed by screening questionnaires. Eur Child Adolesc Psychiatry 14:226-236

27. Kjelsberg E, Nygren P (2004) The prevalence of emotional and behavioural problems in institutionalized childcare clients. Nord $\mathrm{J}$ Psychiatry 58:319-325

28. Klasen H, Woerner W, Wolke D, Meyer R, Overmeyer S, Kaschnitz W, Rothenberger A, Goodman R (2000) Comparing the German versions of the strengths and difficulties questionnaire (SDQ-Deu) and the child behavior checklist. Eur Child Adolesc Psychiatry 9:271-276

29. Koskelainen M, Sourander A, Kaljonen A (2000) The strengths and difficulties questionnaire among finnish school-aged children and adolescents. Eur Child Adolesc Psychiatry 9:277-284

30. Leslie L, Landsverk J, Ezzet-Lofstrom R, Tschann J, Slymen D, Garland A (2000) Children in foster care: factors influencing outpatient mental health service. Child Abuse Negl 24:465-476

31. Marzocchi GM, Capron C, Di Pietro M, Tauleria ED, Duyme M, Frigerio A, Gaspar MF, Hamilton H, Pithon G, Simões A, Thérond C (2004) The use of the strengths and difficulties questionnaire (SDQ) in Southern European countries. Eur Child Adolesc Psychiatry 13:ii40-ii46

32. McCann J, James A, Wilson S, Dunn G (1996) Prevalence of psychiatric disorders in young people in the care system. Br Med J 313:225-233

33. Meltzer H, Gatward R, Goodman R, Ford T (2000) Mental health of children and adolescents in Great Britain. The Stationery Office, London

34. Mount J, Lister A, Bennun I (2004) Identifying the mental health needs of looked after young people. Clin Child Psychol Psychiatry 9:363-382

35. Muris P, Meesters C, van den Berg F (2003) The strenghts and difficulties questionnaire. Further evidence for its reliability and validity in a community sample of Dutch children and adolescents. Eur Child Adolesc Psychiatry 12:1-8

36. Obel C, Heiervang E, Rodriguez A, Heyerdahl S, Smedje H, Sourander A, Guethmundsson ÓÓ, Clench-Aas J, Christensen E, Heian F, Mathiesen KS, Magnússon P, Njarethvík Uu, Koskelainen M, Rønning JA, Stormark KM, Olsen J (2004) The 
strengths and difficulties questionnaire in the Nordic countries. Eur Child Adolesc Psychiatry 13:ii32-ii39

37. Phillips J (1997) Meeting the psychiatric needs of children in foster care: social workers' views. Psychiatr Bull 21:609-611

38. Scholte EM (1997) Exploration of criteria for residential and foster care. J Child Psychol Psychiatry 38:657-666

39. Scott S (2004) Reviewing the research on the mental health of looked after children: Some issues for the development of more evidence informed practice. Int J Child Fam Welf 7:86-97

40. Smedje H, Broman J-E, Hetta J, von Knorring A-L (1999) Psychometric properties of a Swedish version of the strengths and difficulties questionnaire (SDQ). Eur Child Adolesc Psychiatry 8:63-70

41. Treffers PDA, van Widenfelt BM (2000) Dutch translation of the strengths and difficulties questionnaire (SDQ). Internal document Leiden University Medical Center Academic Center for Child and Adolescent Psychiatry, Curium Oegstgeest

42. Van Leeuwen K, Meerschaert T, Bosmans G, De Medts L, Braet C (2006) The strengths and difficulties questionnaire in a community sample of young children in Flanders. Eur J Psychol Assess 22:189-197

43. van Widenfelt BM, Goedhart AW, Treffers PDA, Goodman R (2003) Dutch version of the strengths and difficulties questionnaire (SDQ). Eur Child Adolesc Psychiatry 12:281-289

44. Verhulst FC, van der Ende J, Koot HM (1996) Handleiding voor de CBCL/4-18. Afdeling Kinder- en Jeugdpsychiatrie Sophia, Kinderziekenhuis/Academisch Ziekenhuis Rotterdam/Erasmus Universiteit Rotterdam, Rotterdam

45. Verhulst FC, Van der Ende J, Koot HM (1997a) Handleiding voor de Teacher's Report Form (TRF). Afdeling Kinder- en Jeugdpsychiatrie Sophia Kinderziekenhuis/Academisch Ziekenhuis Rotterdam/Erasmus Universiteit Rotterdam, Rotterdam

46. Verhulst FC, van der Ende J, Koot HM (1997b) Handleiding voor de Youth Self-Report (YSR). Afdeling Kinder- en Jeugdpsychiatrie Sophia Kinderziekenhuis/Academisch Ziekenhuis Rotterdam/Erasmus Universiteit Rotterdam, Rotterdam 